\title{
Evaluation of groundwater vulnerability to pollution using DRASTIC, composite DRASTIC, and nitrate vulnerability models
}

\author{
Mohsen Pourkhosravani ${ }^{1 \times(\mathbb{C}}$, Fatemeh Jamshidi $^{(\mathbb{1}}$, Nasrin Sayari $^{\left.{ }^{(}\right)}$ \\ ${ }^{1}$ Department of Geography and Urban Planning Shahid Bahonar University of Kerman, Kerman, Iran \\ ${ }^{2}$ Department of Water Engineering, Faculty of Agriculture, Shahid Bahonar University of Kerman, Kerman, Iran
}

\begin{abstract}
Background: Groundwater protection against pollution is a very important issue. Groundwater vulnerability maps are useful tools for protecting aquifers and assessing the potential for contamination. Therefore, the purpose of this study was to prepare vulnerability maps and perform sensitivity analysis to identify the most influential factors in the vulnerability of the studied aquifer.

Methods: In this study, groundwater vulnerability to pollution was evaluated using DRASTIC, composite DRASTIC, and nitrate vulnerability (NV) models. Drastic is an index for the systematic assessment of potential groundwater pollution. In this method, the drastic index was calculated from the total weight and rank of the factors. For this purpose, first the factors affecting the pollution transfer, were weighted, ranked, and merged using GIS software. Then, using the overlapping techniques and after applying the necessary weight coefficients on each layer, a map of the vulnerability area of the study aquifer was prepared.

Results: It was revealed that there is a significant linear relationship between all three models with the distribution of nitrate concentration. Accordingly, it was the most efficient NV model, followed by the composite DRASTIC (CD) and DRASTIC models, respectively. Also, in the studied aquifer, the DRASTIC index was between 147 and 136, the combined DRASTIC index was between 70 and 190, and the nitrate index was between 13 and 132 .

Conclusion: Vulnerability assessment of the studied aquifer using DRASTIC, and combined DRASTIC, and NV indices shows that, according to the DRASTIC index, $69.7 \%$ of the studied aquifer was in the medium vulnerability class. Also, according to the combined DRASTIC index, the largest area $(53.62 \%)$ has low vulnerability and $31.56 \%$ has moderate vulnerability. But according to the nitrate index, $77.16 \%$ of the aquifers had very low vulnerability.

Keywords: Environmental pollution, Groundwater, Geographic information systems, Soil, Nitrate Citation: Pourkhosravani M, Jamshidi F, Sayari N. Evaluation of groundwater vulnerability to pollution using DRASTIC, composite DRASTIC, and nitrate vulnerability models. Environmental Health Engineering and Management Journal 2021; 8(2): 129-140. doi: 10.34172/EHEM.2021.16.
\end{abstract}

Article History:

Received: 17 December 2020

Accepted: 7 February 2021

ePublished: 13 May 2021

\section{Introduction}

Groundwater resources are one of the main and most important water resources in large parts of the world, especially in arid and semi-arid regions. On the other hand, high population growth and increasing water needs have led to excessive groundwater extraction in recent years. Also, increasing the use of fertilizers, herbicides, and pesticides in order to increase food production, expand urban development and fungal growth of industries without creating appropriate sewage disposal and treatment systems and, of course, large effluent inflows. Due to the entry of domestic, industrial, and agricultural water into aquifers, the quality of these valuable resources is declining and they are becoming polluted (1-3). In 1993, the US National Science Council defined vulnerability as a tendency for pollutants to reach a specific location in the groundwater system after they formed above the aquifer (4). Preparing vulnerabilities or, in other words, vulnerability zoning is a powerful lowcost method yet, which in determining priority aquifers in terms of monitoring and care, selecting safe areas for urban development, agriculture and industry with minimal damage to groundwater, plays a key role that can help planners and managers protect groundwater. Vulnerability zoning is based on the idea that some areas are more sensitive to groundwater pollution than other areas (5). In fact, with the help of vulnerability maps, potentially dangerous groundwater activities can be placed 
in areas where groundwater aquifers are less threatened. At the same time, these maps identify pollution-sensitive aquifers that need more protection, and thus, facilitate emergency monitoring and cleaning measures. There are several ways to estimate the vulnerability of groundwater aquifers and maps (6).

They can be classified into three classes, process-based or simulation-like methods, statistical methods, and overlapping methods and classification indicators. Among these, the most common and well-known models of overlap and index are the DRASTIC, nitrate vulnerability (NV) and composite DRASTIC models, which have been studied by many researchers (7-16). These models have been used to estimate the vulnerability of groundwater aquifers. Iran with a mean annual rainfall about one-third of the world annual rainfall, has serious problems with water resources (17). Also, the excessive consumption of water resources in recent years has exacerbated the crisis. Due to the importance of studying aquifer vulnerability in groundwater resources management, many studies have been conducted in this regard, for example, Souleymane and Zhonghua assessed groundwater vulnerability to pollution in Senegal River basin using DRASTIC and fuzzy optimization methods. They found that the vadose zone is the main parameter which affects groundwater vulnerability to pollution while net recharge contributes least to pollution in the study area (18). In another study, the chemical quality of groundwater of Orzooiyeh plain, southeast of Iran, was assessed. The results showed that the Electrical ConductivityEC index of $64.3 \%$ of the samples has an optimal level, $71.4 \%$ have the limit of Iran national standard, and only $3.6 \%$ of them have the WHO standard (19). Djémin et al assessed the vulnerability of groundwater in the Dabou region southern of Côte d'Ivoire using the DRASTI index and GS technique. They found that DRASTIC vulnerability map is heavily influenced by the impact of vadose zone and the depth to the water table according to the first test. For the second test, it is the impact of vadose zone, the aquifer media, and the soil media, which have a more significant impact on the vulnerability map (20). Also, Choramin et al evaluated and analyzed chemical parameters of water quality in Bahamanshir river using Schuler, Wilcox, and Piper diagrams. They reported that all quality parameters with significant annual changes as well as all parameters have increased during recent years (21).

Kerman province and Sirjan basin is located in the southeast of Iran in a dry region. For this reason, groundwater resources are one of the main water resources of this area for drinking and agricultural purposes. The aquifer under study is located in the southwest region of Kerman province in Iran. Due to recent droughts, this aquifer has been used extensively, which subsequently, has caused its water level to drop down. Moreover, the use of groundwater resources has been more extensive recently than in formeryears. This overuse of groundwater resources makes studies related to the pathology and zoning of the groundwater losses, unquestionable. Therefore, the aim of the present research was to prepare vulnerability maps of Sirjan aquifer and perform sensitivity analysis to identify the most influential factors in vulnerability of this aquifer.

\section{Materials and Methods \\ Study Area}

Kerman province is located in southeastern Iran with a dry and desert climate. The study area included a 33.2009 $\mathrm{km}^{2}$ area $\left(55^{\circ} 25^{\prime}\right.$ to $56^{\circ} 2^{\prime}$ east longitude and also between $28^{\circ} 57^{\prime}$ to $29^{\circ} 50^{\prime}$ north latitude) located in the southwest part of Kerman province, Iran (Figure 1). Agriculture is one of the most important land uses in the study area. The average annual rainfall in the study area is $142 \mathrm{~mm}$. The relative humidity is $36 \%$ and the average temperature is a maximum of $37^{\circ} \mathrm{C}$ and a minimum of $-1^{\circ} \mathrm{C}$. And the height of this area is 1730 meters above sea level (22).

\section{Methods}

The present study is based on descriptive and analytical methods. In order to assess the vulnerability of the study area against pollution, three models of DRASTIC, composite DRASTIC, and NV were used. Indicators used in this study include depth to water level, net recharge, aquifer environment, the impact of the vadose zone, soil environment, and topography and hydraulic conductivity of these parameters by ArcGIS 10.3 software using interpolation method and inverse distance weighting (IDW). The methods used for the calculation of each of the DRASTIC, composite DRASTIC, and NV models, are as following.

\section{Method of calculating the DRASTIC index}

DRASTIC is an index for the systematic assessment of potential groundwater pollution provided by the United States Environmental Protection Agency (US EPA). In this method, the DRASTIC index is calculated from the total weight and rank of the factors. Higher values indicate that the table is more vulnerable to contamination. Table 1 shows the scope of vulnerabilities corresponding to the DRASTIC index. In this index, each factor is rated on a

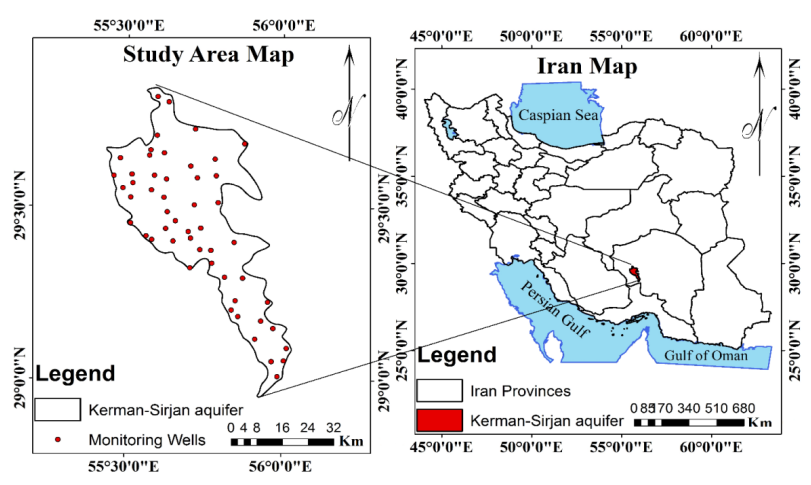

Figure 1. The location of the aquifer. 
Table 1. Vulnerability range in accordance with the DRASTIC index

\begin{tabular}{lc}
\hline Vulnerability & Ranges \\
\hline Very low & $23-46$ \\
\hline Low & $47-92$ \\
\hline Moderate & $93-136$ \\
\hline High & $137-184$ \\
\hline Very high & $185<$ \\
\hline
\end{tabular}

scale of 1 to 10 , indicating the relative pollution potential of that factor for that area. Also, in the DRASTIC index, each of the factors is given a specific weight from 1 to 5. Weight values indicate the relative importance of the factors relative to each other. The DRASTIC index is calculated using the following formula (Eq. 1).

DRASTIC index $=\mathrm{DrDw}+\mathrm{RrRw}+\mathrm{ArAw}$

$+\mathrm{SrSw}+\mathrm{TrTw}+\mathrm{IrIw}+\mathrm{CrCw}$

In the DRASTIC index formula, the letters in the abbreviation include a short form of the factors influencing the DRASTIC model. Also, " $r$ " and "w" refer to points and weights for each factor, respectively (22). The rankings and weights of the factors are shown in Table 2.

\section{Composite DRASTIC index calculation method}

To obtain the composite DRASTIC index, the land use factor was added to the DRASTIC index formula. Therefore, the formula used for the calculation of the composite DRASTIC index is as presented in Eq. (2).

CDRASTIC index $=\mathrm{DrDw}+\mathrm{RrRw}$

$+\mathrm{ArAw}+\mathrm{SrSw}+\mathrm{TrTw}+\mathrm{IrIw}+\mathrm{CrCw}+\mathrm{LrLw}$

Where, $l w$ is the relative weight of the pollution risk associated with land use, which is equal to 5 , and $l r$ is the pollution risk associated with land use. The risk of pollution related to different land uses in the composite DRASTIC index is presented in Table 3 (23). Also, vulnerability ranges related to the CDRASTIC index is shown in Table 4.

\section{Method of calculating the NV index}

Although most land uses have the potential to have a negative impact on groundwater, some uses, such as protected natural areas, can have a protective effect on aquifers. Therefore, in order to overcome this contradiction and also to prepare special vulnerability maps with high accuracy, a new index called NV index. This index has been introduced recently to evaluate both negative and protective effects of different land uses on the groundwater pollution and provide a higher accuracy model than previous models in assessing vulnerabilities. In this model, unlike previous models, the land use rating is multiplied by the hydrogeological parameters, so the achievement of a more accurate output is expected. The $\mathrm{NV}$ index is obtained using Eq. (3).

$\mathrm{NV}$ index $=(\mathrm{DrDw}+\mathrm{RrRw}+\mathrm{ArAw}+\mathrm{SrSw}$

$+\operatorname{Tr} \mathrm{Tw}+\mathrm{IrIw}+\mathrm{CrCw}) \times \mathrm{LU}$

Where $L U$ is the potential risk associated with land use from Table 5 (24). Also, the vulnerability range related to NV index is shown in Table 6.

Table 2. Score and weight related to the factors of DRASTIC index

\begin{tabular}{|c|c|c|c|}
\hline Drastic Factors & Range & Rating ( $r)$ & Weight (w) \\
\hline \multirow{5}{*}{$\begin{array}{l}\text { Water table depth } \\
(\mathrm{m})\end{array}$} & $4.6-9.1$ & 7 & \multirow{5}{*}{5} \\
\hline & $9.1-15.2$ & 5 & \\
\hline & $15.2-22.9$ & 3 & \\
\hline & $22.9-30.5$ & 2 & \\
\hline & $>30.5$ & 1 & \\
\hline \multirow{7}{*}{ Aquifer media } & Sand and gravel & 8 & \multirow{7}{*}{3} \\
\hline & Sand (dominant) and clay & 7 & \\
\hline & Sand and clay & 6 & \\
\hline & Sand & 4 & \\
\hline & Sand and clay & 3 & \\
\hline & Clay and silt & 2 & \\
\hline & Clay & 1 & \\
\hline \multirow{8}{*}{ Soil media } & Gravel & 10 & \multirow{8}{*}{2} \\
\hline & Sand & 9 & \\
\hline & Gravel and sand & 8 & \\
\hline & Sand and clay & 6 & \\
\hline & Gravel and clay & 4 & \\
\hline & Sand and clay & 3 & \\
\hline & Clay and silt & 2 & \\
\hline & Clay & 1 & \\
\hline \multirow{2}{*}{$\begin{array}{l}\text { Topography or } \\
\text { slope (\%) }\end{array}$} & $0-2$ & 10 & \multirow[t]{2}{*}{1} \\
\hline & $2-6$ & 9 & \\
\hline \multirow{8}{*}{$\begin{array}{l}\text { The impact of the } \\
\text { vadose zone }\end{array}$} & Sand and large rubble & 10 & \multirow{8}{*}{5} \\
\hline & Gravel and sand & 8 & \\
\hline & Sand (dominant) and clay & 7 & \\
\hline & Sand and clay & 6 & \\
\hline & Gravel and clay & 4 & \\
\hline & Sand and clay & 3 & \\
\hline & Clay and silt & 2 & \\
\hline & Clay & 1 & \\
\hline \multirow{5}{*}{$\begin{array}{l}\text { Hydraulic } \\
\text { conductivity (m/day) }\end{array}$} & $0.8-4.1$ & 1 & \multirow{5}{*}{3} \\
\hline & $4.1-12.2$ & 2 & \\
\hline & $12.2-28.5$ & 4 & \\
\hline & $28.5-40.7$ & 6 & \\
\hline & $40.7-81.5$ & 8 & \\
\hline \multirow{3}{*}{ Net recharge } & $5-7$ & 3 & \multirow{3}{*}{4} \\
\hline & $7-9$ & 5 & \\
\hline & $9-11$ & 8 & \\
\hline
\end{tabular}


Table 3. Pollution hazard rating related to different land uses based on the CDRASTIC index

\begin{tabular}{ll}
\hline Land use types & Ir \\
\hline Urban areas & 8 \\
Orchards & 6 \\
\hline Uncultivated land & 5 \\
\hline
\end{tabular}

Table 4. Vulnerability ranges related to the CDRASTIC index

\begin{tabular}{lc}
\hline Vulnerability & Ranges \\
\hline Very low & $<100$ \\
\hline Low & $100-145$ \\
\hline Moderate & $145-190$ \\
\hline High & $190-235$ \\
Very high & $>235$ \\
\hline
\end{tabular}

Table 5. Potential hazard rating related to land use in the NV method

\begin{tabular}{ll}
\hline LU & Land use types \\
\hline 1 & Urban areas \\
\hline 0.8 & Orchards \\
\hline 0.6 & Non-irrigated crops \\
\hline 0.3 & Uncultivated land and semi-natural areas \\
\hline 0.2 & Forests and natural areas \\
\hline
\end{tabular}

Water table depth (D)

With increasing water depth, the contamination potential of the table decreases. In order to prepare a depth map to the water level, the information of 52 Kerman-Sirjan aquifer wells, which were obtained from the Kerman Water and Regional Organization (KWRO), was used. The position and depth of the static surface of the wells in the area entered Excel 2016, and then, their format was changed to the acceptable one for the Arc GIS software. Afterwards, using the IDW internalization method in the GIS software, a map of the static surface depth was prepared and ranked according to Table 2.

\section{Net recharge}

Piscopo method has been used to prepare the nutrition layer. Piscopo replaced the method provided by the USEPA with the net recharge parameter based on rainfall, slope, and soil permeability. To calculate the percentage of slope, a digital elevation model (DEM) was prepared from the study area. The slope of the area was then extracted using the prepared model and classified using Table 7 criteria. The soil map of the region was also prepared and classified according to the criteria of Table 7. After preparing all the above-mentioned maps to obtain the nutrient layer, the slope and soil maps were overlapped with the rainfall area in the region, which is equal to 1 in the study area because the rainfall is less than $500 \mathrm{~mm}$. Piscopo's equation used for calculating the net recharge potential of the study area is as presented in Eq. (4):

Net recharge factor $=$ slope percentage + rainfall rate + soil permeability

\section{Aquifer media (A)}

This factor controls the flow of groundwater in the aquifer (22). To prepare this layer, the information of the well drilling logo, which was obtained from the KWRO, was used. Then, according to the model, for each of the wells according to the material of the well logo, a numerical value was given based on Table 2. Finally, the raster map of the aquifer environment in the GIS environment was prepared.

\section{Soil media (S)}

This part represents the highest part of the unsaturated region that continues to the point of penetration of plant roots and the activities of organic organisms. In order to prepare the soil layer related to the study area, the excavation wells of the region's wells and the maps prepared by the Natural Resources Department were used. The soil type was determined to a depth of $2 \mathrm{~m}$ and ranked according to Table 2. Finally, the raster map of the

Table 6. The vulnerability range related to the NV index

\begin{tabular}{lc}
\hline Ranges & Vulnerability \\
\hline$<70$ & Very low \\
\hline $70-110$ & Low \\
$110-150$ & Moderate \\
$150-190$ & High \\
$>190$ & Very high \\
\hline
\end{tabular}

Table 7. Weight, rating, and range of the net recharge parameter

\begin{tabular}{|c|c|c|c|c|c|c|c|c|}
\hline \multicolumn{2}{|c|}{ Slope (\%) } & \multicolumn{2}{|c|}{ Rainfall } & \multicolumn{2}{|c|}{ Soil Permeability } & \multicolumn{3}{|c|}{ Net Recharge } \\
\hline $\begin{array}{l}\text { Range } \\
(\%)\end{array}$ & Factor & $\begin{array}{c}\text { Range } \\
\text { (mm/year) }\end{array}$ & Factor & Range & Factor & $\begin{array}{c}\text { Range } \\
\text { (cm/year) }\end{array}$ & Rating & Weight \\
\hline$<2$ & 4 & $>850$ & 4 & High & 5 & $11-13$ & 10 & \\
\hline $2-10$ & 3 & $700-850$ & 3 & Moderate to high & 4 & $9-11$ & 8 & \\
\hline $10-33$ & 2 & $500-700$ & 2 & Moderate & 3 & $7-9$ & 5 & 4 \\
\hline \multirow[t]{2}{*}{$33<$} & 1 & $<500$ & 1 & Low & 2 & $5-7$ & 3 & \\
\hline & & & & Very low & 1 & e3-5 & 1 & \\
\hline
\end{tabular}


soil environment was prepared in the GIS environment.

\section{The impact of the vadose zone (I)}

This layer is placed between the soil layer and the aquifer. In order to prepare the layer of unsaturated environment, the information of the wells logo in the region, which was prepared by the KWRO, was used. By studying the logos according to the composition and size of the grains, they were ranked according to the rankings presented in Table 2. At the end, the IDW method was used to generalize the ranks to the whole area and rank the parameters.

\section{Topographic layer (T)}

To prepare the topographic layer, first, the DEM of the area was prepared by the topographic maps of the area, then, in Arc GIS environment using slope tool, the slope for DEM area was calculated and ranked according to Table 2.

\section{Hydraulic conductivity layer (C)}

In this study, the information obtained from the transmission capability and the saturation section of the aquifer was used to determine the hydraulic conductivity. Thus, the information obtained, along with the location of each well, was transferred from the Excel environment to the GIS software environment and converted to a point layer. At the end, the IDW method was used to rank and generalize the data of hydraulic conductivity related to the sample well to the whole area.

\section{Land use layer $(L)$}

Land use means the use of land to meet various human needs. Groundwater is significantly associated with land use. In order to prepare a land use map of the study area, remote sensing method and geographical information system were used.

\section{Sensitivity analysis}

Despite the acceptance of the DRASTIC method, some scientists, such as Barbara et al (25) believe that there is no need to use the seven factors used in the DRASTIC model, and that this model responds with fewer factors or that the weights and rates attributed to the DRASTIC model are not accurate enough. Conversely, some researchers, such as Napolitano and Fabri, also believe that the weights and accruals assigned to the DRASTIC index are accurate enough and there is no reason to doubt these coefficients (26). Therefore, in order to eliminate these doubts, a statistical method called sensitivity analysis was performed. During the sensitivity analysis steps, the input parameters of the model are changed and the system response to these changes is evaluated. As a result, the sensitivity of each factor is determined. The effectiveness of each of the factors used was evaluated to assess the vulnerability of the study area using two types of factor sensitivity analysis and single factor sensitivity analysis.

\section{Sensitivity analysis of parameter deletion}

The method, developed by Manson and Saboda, examines changes in the vulnerability index by removing one or more layers according to Eq. (4) (27).

$\mathrm{S}=\frac{\left|(\mathrm{V} / \mathrm{N})-\left(\mathrm{V}^{\prime} / \mathrm{n}\right)\right|}{\mathrm{V}} \times 100$

In this regard, $S$ is the sensitivity level, $V$ and $V^{\prime}$ are the non-turbulent index and turbulent index, respectively, and $N$ and $n$ are the number of information layers used to calculate $V$ and $V$, respectively. In this method, first, each of the factors used in the model is removed separately from the calculations and the remaining layers are overlapped again and a new vulnerability index is obtained. In this way, the effect of the removed layer in the model can be examined to some extent. In fact, this method can be used to identify the most effective factor on pollution.

\section{Single parameter sensitivity analysis}

In this method, first proposed by Napolitano and Fabri, the actual or effective weight of each factor is obtained by the following equation and compared with its theoretical weight in Eq. (5) (26).

$\mathrm{W}=\left(\frac{\mathrm{P}_{\mathrm{r}} \times \mathrm{P}_{\mathrm{w}}}{\mathrm{V}}\right) \times 100$.

Where $W$ is the effective weight of the parameter, $P_{r}$ and $P_{w}$ are the rank and weight of each factor, respectively, and $V$ is the overall vulnerability index.

\section{Verification of prepared models}

One way to ensure that the resulting models and maps correctly determine the vulnerability of the area is to use a scattering concentration of certain pollutants, such as nitrate. Thus, using the concentration of nitrate ion in the aquifer wells of the study area, a zoning map of nitrate pollution in the region can be prepared. Then, by overlapping this map on the potential water permeability maps of the study area, the correlation between these two maps is determined. If in the aquifer areas that show high vulnerability, the concentration of nitrate is also high, and conversely, so the efficiency of the vulnerability models used can be confirmed. For this purpose, first, the concentration of nitrate in groundwater in different parts of the plain was determined, then, the data file was converted to an acceptable format in the GIS software and entered the software, and using the IDW method, the area within the border of the region was internalized, and thus, nitrate zoning map was prepared in the region.

\section{Regression test}

In order to determine the correlation and statistically significant correlation between the models used with the regional nitrate concentration distribution map and also to determine the model with a higher ability in identifying areas that are at risk of nitrate contamination, 
the regression test was used in SPSS version 19.

Results

Water table depth (D)

Based on the depth ranking map (Figure 2), and the table of rankings related to the parameters of the DRASTIC model

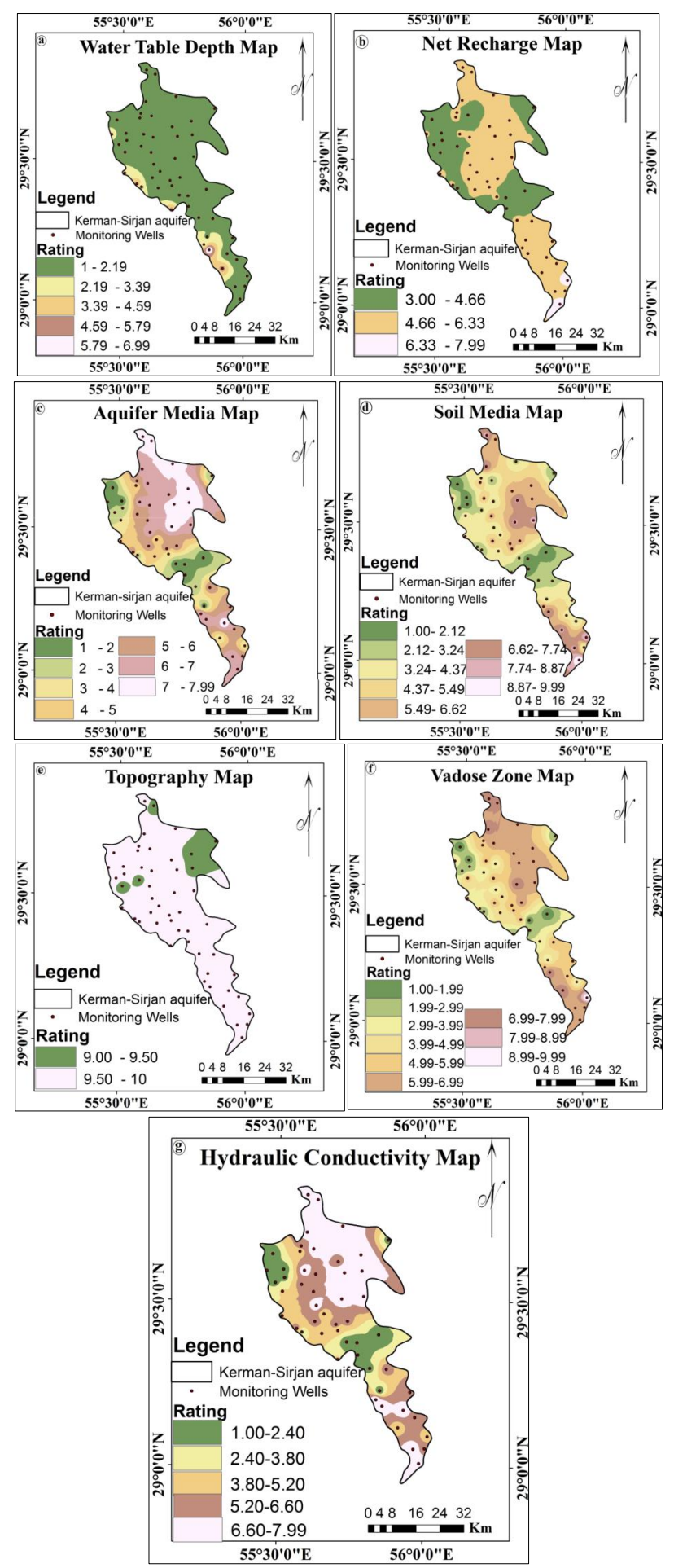

Figure 2. Ranked maps of the aquifer in the study area: a) Water table depth, b) Net recharge, c) Aquifer media, d) Soil media, e) Topography (\% slope), f) The impact of the vadose zone, g) Hydraulic conductivity. in the study area (2), reduce the depth of groundwater level from the northeast of the aquifer to the southwest of the aquifer.

So that the depth of impact to the static level varies from 151 meters in the northeastern part of the aquifer to $8 \mathrm{~m}$ in the southwest. In terms of size, most of the aquifer area has a depth above 30 meters, which is low in terms of pollution potential.

\section{Net recharge $(R)$}

As shown in Figure 2 and Table 2, net recharge in aquifer is divided into 3 classes $(3,5$, and 8$)$ based on the Piscopo method. In terms of area, $57.43 \%$ of the study area is ranked as the $5^{\text {th }}$ class, $40.32 \%$ of the study area is ranked as the 3 rd class and $2.24 \%$ of the study area is ranked as the $8^{\text {th }}$ class. Rank 8 indicates the highest contamination potential. Numerical rank for the northwestern and northeastern regions of the aquifer and parts of the aquifer is 3 .

\section{Aquifer media (A)}

Sediments forming the aquifer in the study area are the result of erosion of adjacent heights. Sediments originating in the northern and eastern highlands, and due to the spread of limestone and precious stones mixed in these heights, it was mainly coarse grains and to the west of the plain, the grain size decreases. In terms of area, aquifers have grades 6,7 , and 8 , indicating that most aquifers have coarse-grained sediments. Class 8 shows the highest potential for contamination and class 1 shows the lowest potential for contamination.

\section{Soil media (S)}

The eastern half of the study area has light texture and coarse grains due to the presence of conifers. To the west, the soil texture is granulated and its clay content is increased. According to the soil environment map, by moving from the northeast and north of the aquifer to the west, the soil texture becomes finer. Also, by moving from the south and southwest of the aquifer to the middle parts of the aquifer, the soil texture becomes finer. The soil media of the aquifer in the study area is divided into 8 classes $(1,2,3,4,6,8,9$, and 10), among which class 10 indicates the highest potential for pollution and class 1 shows the lowest potential for pollution.

\section{Topographic layer (T)}

The slope of the topography is inversely related to the potential for contamination. According to Figure 2 and Table 2, the study area aquifer slope is placed in 2 classes (9 and 10). Class 9 is much less widespread and class 10 provides the highest potential for contamination.

\section{The impact of the vadose zone (I)}

The impact of the vadose zone of the study area is divided into 8 classes $(1,2,3,4,6,7,8$, and 10$)$, among which class 
10 indicates the highest potential for contamination and class 1 indicates the lowest potential for contamination. According to the map of the impact of the vadose zone, by moving from the north and parts of the northeast of the aquifer to the northwest and west, the sediments become more precipitated. Also, by moving from the south and southwest of the aquifer to the middle parts of the aquifer, the sediments become finer.

\section{Hydraulic conductivity layer (C)}

Hydraulic conductivity layer depends on the type of soil, the middle area, and the layer. According to the studies of the mathematical model, the hydraulic conductivity of the aquifer in the study area varies from 0.8 meters per day to a maximum of 81.5 meters per day, and the whole aquifer is placed in 5 classes $(1,2,4,6$, and 8). Hydraulic conduction is greater in the north, southeast, and parts of the northeast than in other parts due to the expansion of coarse-grained sediments, indicating that the potential for pollution in these areas is increasing. These results are shown in Figure 2 and Table 2.

\section{Aquifer land use map}

Figure 3 shows the land use map of the study area. As shown in this figure and Table 8 , there are three main types of use in the region. The main land use in the region is barren lands, which with an area of $1220.14 \mathrm{~km}^{2}$, includes $60.72 \%$ of aquifers, which is mainly the east of aquifers. The gardens, with an area of $731.76 \mathrm{~km}^{2}$, cover $36.43 \%$ of the aquifer, which is mainly the west of the aquifer. Urban areas with an area of $57.43 \mathrm{~km}^{2}$ cover $2.85 \%$ of the aquifer.

\section{Discussion}

The aquifer vulnerability index: Final output of DRASTIC index

Figure 4 shows the vulnerability map. As shown in this figure and Table 9, the water intake strategy index of the study area is between 47 and 136. The aquifer in the study

Table 8. Percentage of land use area

\begin{tabular}{lcc}
\hline Land Use & Area $\left(\mathrm{Km}^{2}\right)$ & Area (\%) \\
\hline Urban areas & 57.43 & 2.85 \\
\hline Uncultivated land & 1220.14 & 60.72 \\
\hline Orchards & 731.76 & 36.43 \\
\hline Sum & 2009.33 & 100 \\
\hline
\end{tabular}

Table 9. Classification of the aquifer in the study area using DRASTIC index

\begin{tabular}{lccc}
\hline \multirow{2}{*}{ Vulnerability } & \multicolumn{3}{c}{ DRASTIC index } \\
\cline { 2 - 4 } & Ranges & Area $\left.\mathbf{( k m}^{2}\right)$ & Area $(\%)$ \\
\hline Low & $47-92$ & 608.67 & 30.30 \\
\hline Moderate & $92-136$ & 1400.67 & 69.70 \\
Sum & & 2009.33 & 100 \\
\hline
\end{tabular}

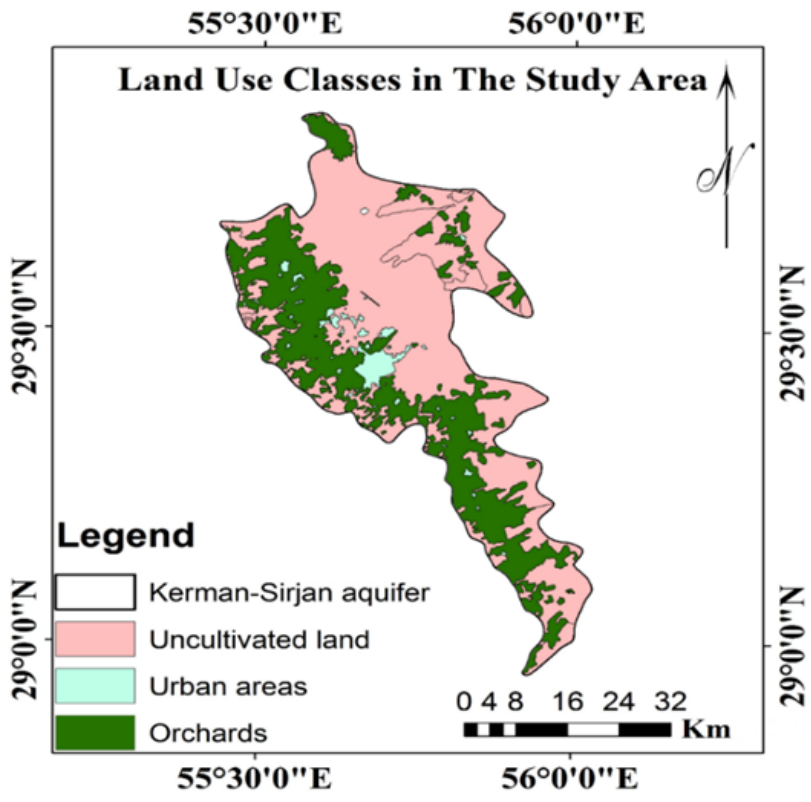

Figure 3. Map of land use of the aquifers in the study area.

$55^{\circ} 30 \prime 0 "$ '

$56^{\circ} 0^{\prime} 0 " \mathrm{E}$

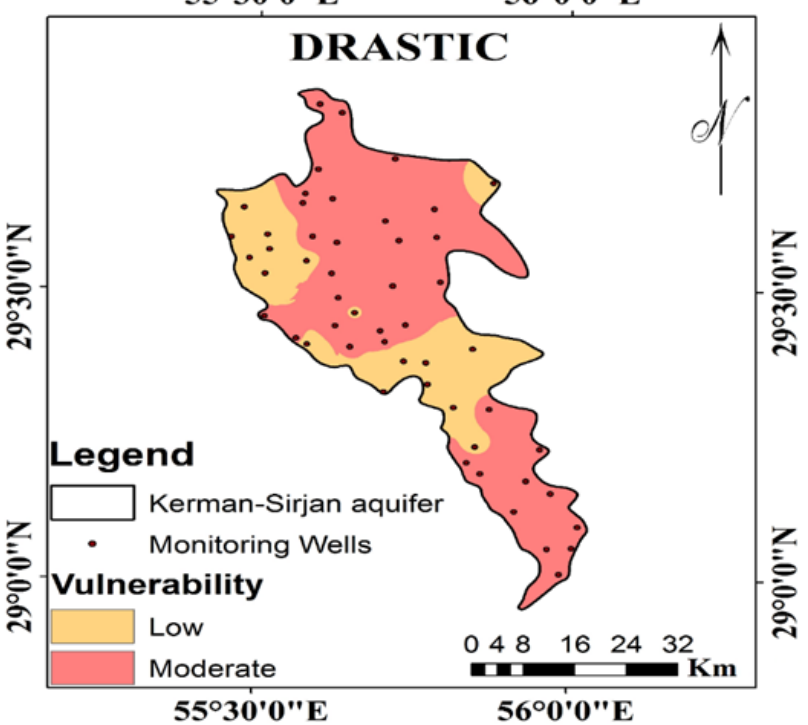

Figure 4. The vulnerability map of the aquifer in the study area by DRASTIC index.

area, in terms of the vulnerability to pollutants, is in two classes of low and moderate vulnerability. Thirty percent of the area is in the low-damage class, located in the northwest and parts of the aquifer. Also, $69.70 \%$ of the region is in the middle vulnerability class. In general, by moving from the north, east, and northeast to the northwest and the middle parts of the aquifer, and from the south to the middle of the aquifer, the vulnerability increases. Collins et al (28) assessed the vulnerability of Kodaganar watershed using a DRASTIC model. The studied aquatic strategy index in terms of vulnerability is divided into four classes of very low, low, medium, and high vulnerability. Also, most of the aquifer area has low vulnerability. In the present study, 
according to the DRASTIC index, the study area aquifer is in two classes of low and medium damage in terms of vulnerability, indicating that $69.70 \%$ of the aquifer area is in moderate vulnerability class.

\section{Preparing the rated land use layer $(L)$}

In order to prepare 1 layer, the land use maps (Figure 3 and Table 3) were used. According to Table 3, the lowest rank (5) is related to the uncultivated areas and barren lands, which poses the least risk of nitrate deposition for groundwater resources, and the highest rank (8) is related to the residential areas, which causes the highest risk of nitrate deposition of groundwater aquifers, and also belongs to the $6^{\text {th }}$ rank orchards. Figure 5 shows the land use map for the aquifer in the study area. As shown in this map, due to the larger area of the uncultivated areas and barren lands, most of the aquifer area is ranked $5^{\text {th }}$, which poses the least risk of nitrate degradation for groundwater resources.

Aquifer vulnerability index: The final output of the composite DRASTIC index

Figure 6 shows the vulnerability map of the aquifer in the study area by the composite DRASTIC index. As shown in this figure and Table 10, the index of combined strategy, in the study area aquifer was between 70 and 190 and is categorized into three classes of very low, low, and moderate vulnerability. $14.82 \%$ of the study area is in a very low vulnerability class, which includes parts of the northwest and between the aquifers. Most of the area (53.62\%) has low vulnerability and $31.56 \%$ of the region is in the middle vulnerability class, which includes parts of the east, north, south, and southwest of the aquifer in the study area. Malakootian and Nozari (22) found in a 2019 assessed the use of a composite DRASTIC and DRASTIC models to evaluate the vulnerability of a garden aquifer. According to the results of the combined aquatic strategy model, they classified the aquifer in question as very low, low, medium, high, and very high in terms of vulnerability to pollution. Also, most of the aquifer area has low vulnerability. In the present study, the studied aquifer is divided into three classes: Very low, low, and medium vulnerability.

Table 10. Classification of the aquifer in the study area using composite DRASTIC index

\begin{tabular}{lccc}
\hline \multirow{2}{*}{ Vulnerability } & \multicolumn{3}{c}{ Composite DRASTIC Index } \\
\cline { 2 - 4 } & Ranges & Area $\left(\mathbf{k m}^{2}\right)$ & Area (\%) \\
\hline Very low & $70-100$ & 297.82 & 14.82 \\
\hline Low & $100-145$ & 1077.53 & 53.62 \\
\hline Moderate & $145-190$ & 633.98 & 31.56 \\
\hline Sum & & 2009.33 & 100 \\
\hline
\end{tabular}

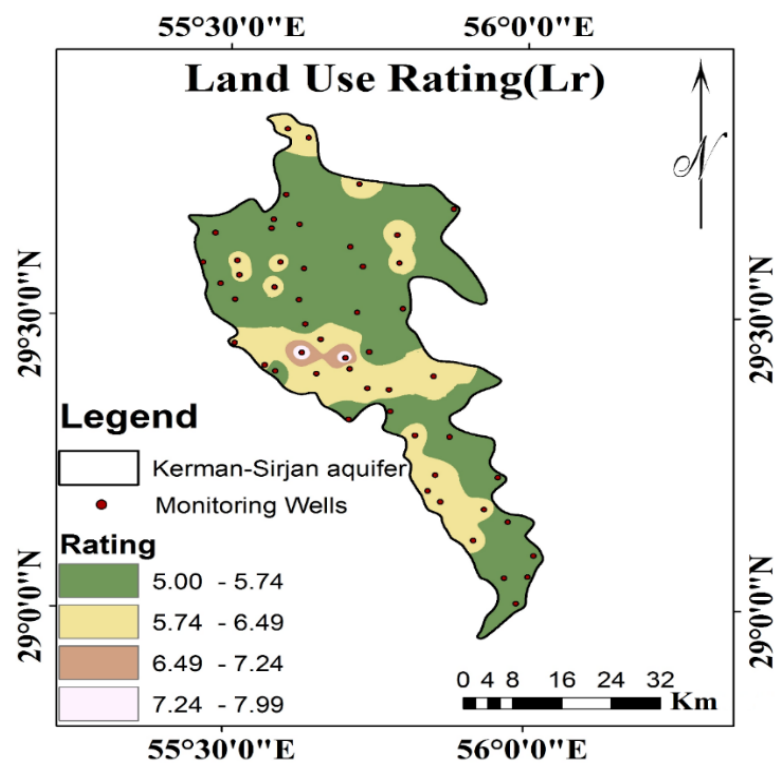

Figure 5. Ranked layer of land use $(L)$ of the aquifer in the study area.

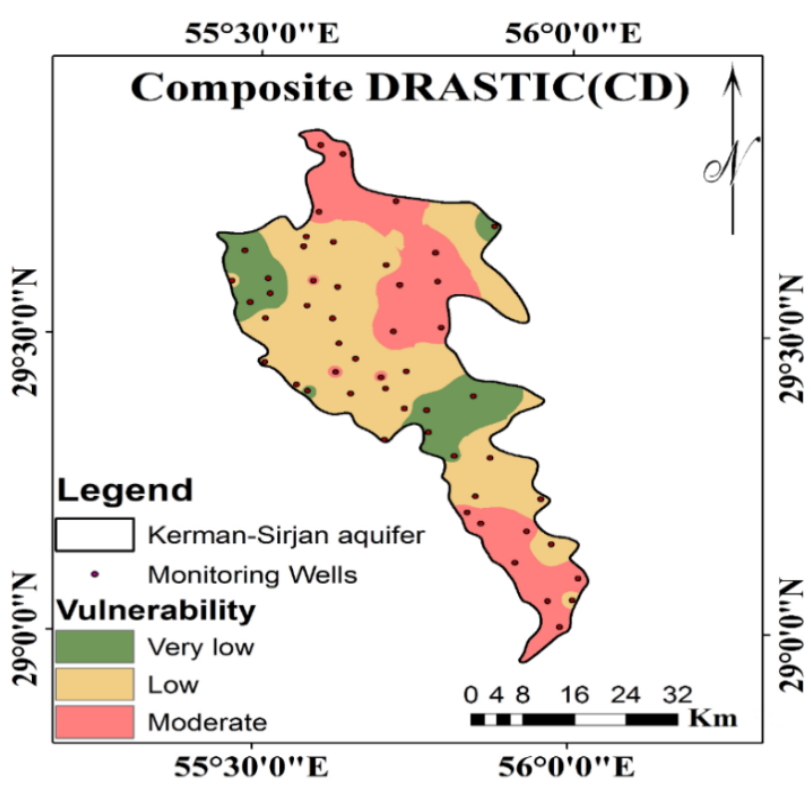

Figure 6. The vulnerability map of the study area by composite DRASTIC index.

Preparation of Lu layer or potential hazard related to land use

In order to prepare the LU layer, the land use map of Figure 3 and Table 5 was used. According to this table, the rating $(0.3)$ is related to uncultivated lands and semi-natural areas, which poses the least risk of nitrate to groundwater resources and covers a large part of the aquifer in the study area. Rank (0.8) is related to the aquifers garden studied and the highest rank (1) is related to urban areas, which is the most dangerous cause of contamination of groundwater aquifers. Figure 7 shows the LU map of the aquifer in the study area. 
Aquifer vulnerability index: Final output of nitrate vulnerability (NV) model

Figure 8 shows the map of the aquifer vulnerability in the study area using NV method. As shown in this figure and Table 11, NV index of this aquifer was between 13 and 132 and was categorized in three classes of very low, low, and moderate vulnerability. Most of the area is very vulnerable. This type of vulnerability covers about $77.16 \%$ of the aquifers in the study area. Also, $22.6 \%$ of the aquifers are in the low vulnerability class and $0.76 \%$ of the aquifers are in the middle vulnerability class (24). In a study conducted Baghapour et al, the vulnerability of groundwater in Shiraz plain was assessed using artificial neural network models,

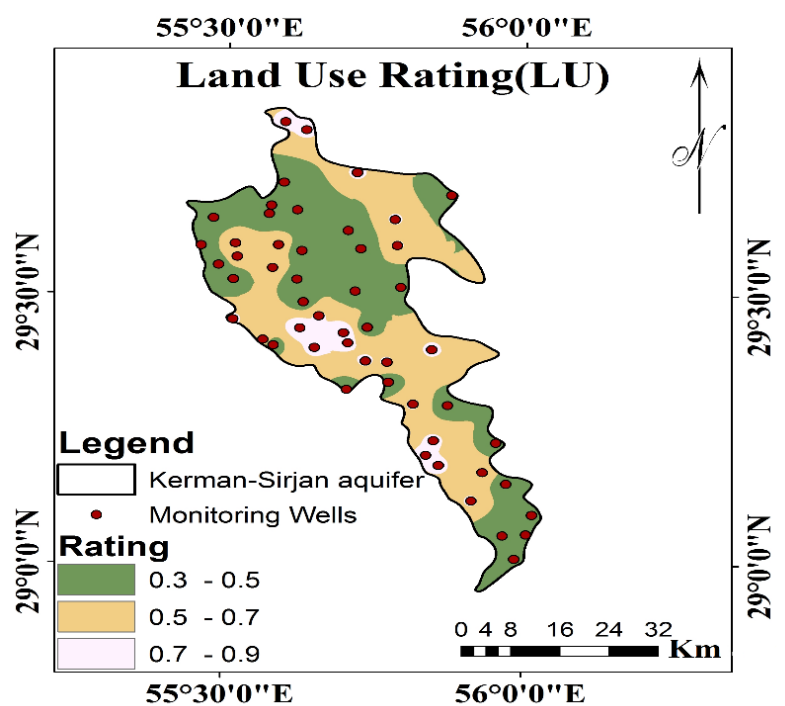

Figure 7. The possible risk related to land use rating of the aquifer in the study area.

5530'0"' E

$56^{\circ} 0^{\prime} 0^{\prime \prime} \mathrm{E}$

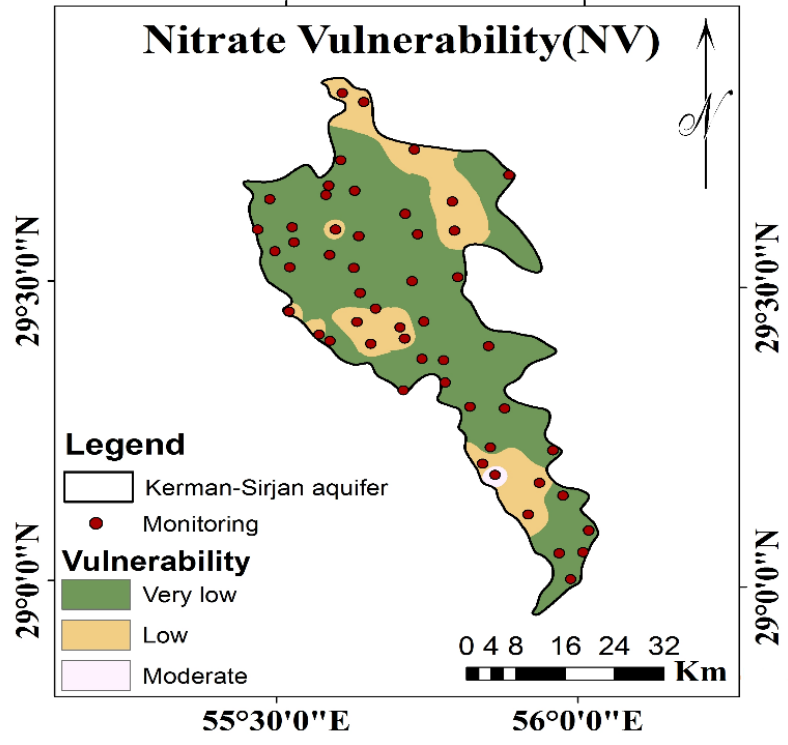

Figure 8. The vulnerability map of the study area by nitrate vulnerability (NV) method.
Table 11. The nitrate vulnerability (NV) index classification of the aquifer in the study area

\begin{tabular}{lccc}
\hline \multirow{2}{*}{ Vulnerability } & \multicolumn{3}{c}{ NV index } \\
\cline { 2 - 4 } & Ranges & Area $\left(\mathbf{k m}^{2}\right)$ & Area $(\%)$ \\
\hline Very low & $13-70$ & 1550.55 & 77.16 \\
\hline Low & $70-110$ & 443.34 & 22.06 \\
\hline Moderate & $110-132$ & 15.44 & 0.76 \\
\hline Sum & & 2009.33 & 100 \\
\hline
\end{tabular}

$\mathrm{NV}$ and combined strategy. According to the results of NV model, the studied aquifer was placed in three classes of very low, low, and medium vulnerability, most of the plain area has very low vulnerability (23), while in the present study, most of the aquifer area according to this model is very vulnerable.

\section{DRASTIC model sensitivity analysis}

Sensitivity analysis of parameter removal (layer removal) Table 12 shows the vulnerability index as a result of the removal of layers for the aquifer in the study area. The results in this table show that the most important parameter affecting the vulnerability index is the unsaturated environment, which has the highest effective weight with an average change of 1.65. Afterwards, the parameters of water table depth, soil media, net recharge, topography, and hydraulic conductivity with average changes of 1.29 , $0.96,0.92,0.89$, and 0.68 are placed in the next ranks of sensitivity, respectively. Finally, aquifer vulnerability with an average change of 0.67 has the lowest sensitivity to the aquifer perimeter.

\section{Analysis of single-parameter sensitivity}

Table 13 presents the statistical results of the singleparameter sensitivity analysis. As shown in this table, the effective weight and the theoretical parameters of the strategy do not completely match each other, and in some cases, have significant differences. According to the results of Table 13, the parameter of the unsaturated environment is the most effective parameter in assessing the vulnerability, which also confirms the results of the sensitivity analysis of the removal of layers. The average effective weight of this parameter is more than the theoretical weight assigned to it by the DRASTIC model. It should be noted that after the unsaturated environment with an average effective weight of 23.77, the net recharge, hydraulic conductivity, aquifer media, topography, and water table depth in the vulnerability index have the greatest impact, respectively. Soil media with an effective weight of 8.47 has the least effect on the aquifer vulnerability index.

\section{Analysis of hypersensitivity model in hybrid strategy} Sensitivity analysis of parameter removal (layer removal) Table 14 shows the variability of the specific vulnerability index of the CD index as a result of removing the layers 
Table 12. Statistical results of sensitivity analysis by parameter remove method for DRASTIC index

\begin{tabular}{lcccc}
\hline \multicolumn{4}{l}{ Sensitivity } & \multicolumn{3}{l}{ of variability index (S) $(\%)$} & Removed parameters \\
\cline { 1 - 3 } SD & Min. & Max. & Ave. & $\mathrm{D}$ \\
\hline 0.56 & 0.10 & 2.70 & 1.29 & $\mathrm{R}$ \\
\hline 0.79 & 0.01 & 2.61 & 0.92 & $\mathrm{~A}$ \\
\hline 0.43 & 0 & 1.74 & 0.67 & $\mathrm{~S}$ \\
\hline 0.46 & 0.11 & 1.78 & 0.96 & $\mathrm{~T}$ \\
\hline 0.39 & 0.07 & 1.78 & 0.89 & $\mathrm{I}$ \\
\hline 0.94 & 0.09 & 4.11 & 1.65 & $\mathrm{C}$ \\
\hline 0.44 & 0.02 & 1.74 & 0.68 & \\
\hline
\end{tabular}

Table 13. Statistical results of single-parameter sensitivity analysis

\begin{tabular}{|c|c|c|c|c|c|c|}
\hline \multicolumn{4}{|c|}{ Effective weight (\%) } & \multirow{2}{*}{$\begin{array}{l}\text { Theoretical } \\
\text { weight (\%) }\end{array}$} & \multirow{2}{*}{$\begin{array}{c}\text { Theoretical } \\
\text { weight }\end{array}$} & \multirow{2}{*}{ Parameters } \\
\hline SD & Min. & Max. & Ave. & & & \\
\hline 6.39 & 3.40 & 30.48 & 8.64 & 21.74 & 5 & D \\
\hline 4.99 & 10.81 & 30 & 19.58 & 17.39 & 4 & $\mathrm{R}$ \\
\hline 4.81 & 3.79 & 21.68 & 13.74 & 13.04 & 3 & A \\
\hline 2.80 & 3.60 & 13.60 & 8.47 & 8.70 & 2 & $S$ \\
\hline 5.12 & 6.02 & 25 & 11.33 & 4.35 & 1 & $\mathrm{~T}$ \\
\hline 6.41 & 11.11 & 38.96 & 23.77 & 21.74 & 5 & 1 \\
\hline 4.95 & 3.79 & 23.76 & 14.43 & 13.04 & 3 & $\mathrm{C}$ \\
\hline
\end{tabular}

Table 14. Statistical results of sensitivity analysis by parameter remove method for composite DRASTIC model

\begin{tabular}{lllll}
\hline \multicolumn{3}{l}{ Sensitivity } & of variability index (S) $(\%)$ & \multicolumn{2}{l}{ Removed parameters } \\
\cline { 1 - 3 } SD & Min. & Max. & Ave. & D \\
\hline 0.40 & 0.06 & 1.55 & 1.01 & $\mathrm{R}$ \\
\hline 0.31 & 0.01 & 1.15 & 0.38 & $\mathrm{~A}$ \\
\hline 0.40 & 0.01 & 1.38 & 0.51 & $\mathrm{~S}$ \\
\hline 0.36 & 0.12 & 1.43 & 0.84 & $\mathrm{~T}$ \\
\hline 0.27 & 0.02 & 1.05 & 0.64 & $\mathrm{I}$ \\
\hline 0.63 & 0.02 & 2.65 & 1.01 & $\mathrm{C}$ \\
\hline 0.38 & 0.01 & 1.38 & 0.51 & $\mathrm{~L}$ \\
\hline 1.07 & 0.29 & 4.33 & 1.54 & \\
\hline
\end{tabular}

for the aquifer in the study area. As shown in this table, the most important parameter affecting the vulnerability index is land use, which has the highest effective weight with an average of 1.54 changes. This indicator also shows sensitivity to the elimination of the parameter of the unsaturated environment and the depth of the standing surface.

\section{$B$ - Analysis of single-parameter sensitivity}

Table 15 presents the results of the sensitivity analysis of the single-parameter model of the $\mathrm{CD}$ index. According to this table, the theoretical weight and effective weight of $\mathrm{CD}$ index parameters show significant differences. Land use parameter is the most effective parameter in assessing vulnerability, which also confirms the results of the sensitivity analysis of layer removal. The average effective weight of this parameter is more than the theoretical weight assigned to it. The effective weight of net recharge, aquifer media, topography, the impact of the vadose zone and hydraulic conductivity is more than the theoretical weight assigned to them, and the effective weight of static depth and soil media parameters is less than their theoretical weight.

Wire distribution zoning map of the aquifer in the study area

It is a map that can determine the accuracy of the models used in identifying vulnerable areas. The highest levels of nitrate are found in parts of the eastern, southeastern, and northern regions, which were also identified as the most vulnerable by vulnerability models. In other words, the way the nitrate concentration is distributed in the study area can confirm the accuracy of the models (Figure 9).

\section{Regression analysis}

In order to perform this test and determine the statistical relationship between the output of DRASTIC models, nitrate compound strategy and vulnerability with the distribution of nitrate concentration in the study area, nitrate data from 52 wells, piezometers, and groundwater sources were used in the aquifer in the study area. If there is a significant statistical relationship between them, the accuracy of the models is confirmed and shows that we have achieved the goals of the project. The results of the regression analysis showed that there was a significant linear relationship between all three models with the nitrate map. The values and statistical equations for all

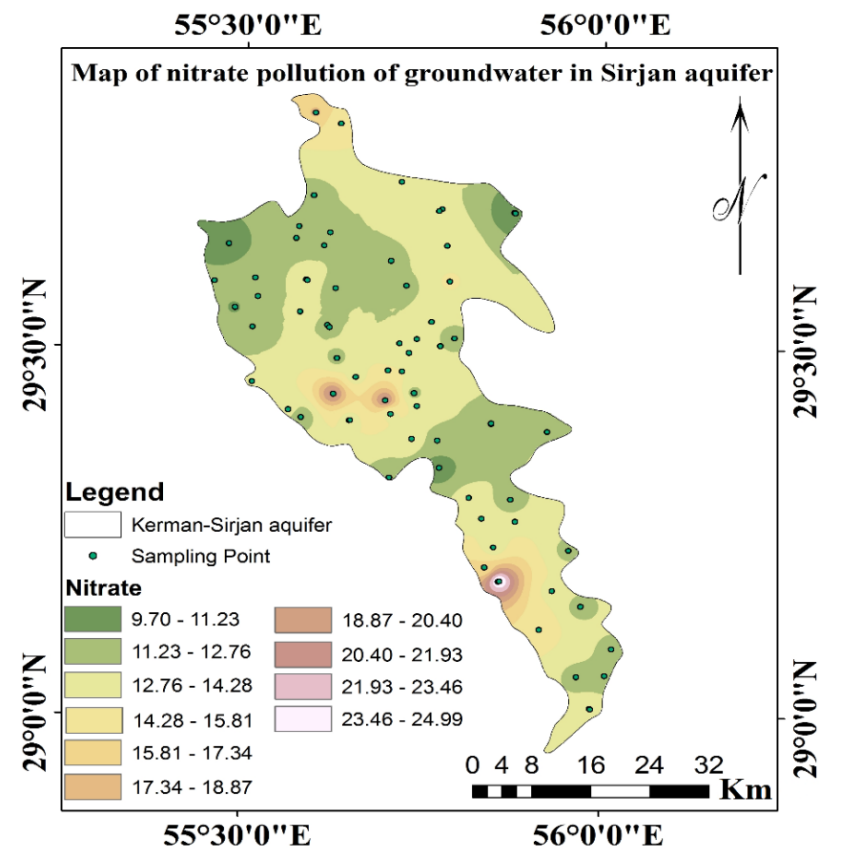

Figure 9. The zoning map of nitrate concentration in the aquifer in the study area. 
three models are as follows. Also, based on these results, NV index has a higher efficiency in predicting vulnerable areas (Table 16).

\section{Conclusion}

In this study, due to the hydrological and hydrogeological characteristics of the aquifer in the study area, the vulnerability of this aquifer was zoned against pollutants. For this purpose, three indicators including DRASTIC, composite DRASTIC (CD), and NV were used. The results show that, according to this aquifer strategy index, $30.30 \%$ of the region is in the low vulnerability class, and $69.70 \%$ of the region is in the middle vulnerability class. Also, based on the results of the composite water supply strategy index of the study area, $14.82 \%$ of the region is in a very low vulnerability class. Most of the area (53.62\%) has low vulnerability, and $31.56 \%$ of the area is in the middle vulnerability class. Also, based on the results of the aquifer NV index, about $77.16 \%$ of the aquifer has very low vulnerability. Also, $22.6 \%$ of the aquifers are in the low vulnerability class and $0.76 \%$ of the aquifers are in the middle vulnerability class. The output of all three models showed that the northwest and northeast regions, as well as the middle parts of the aquifer were the least vulnerable areas. The nitrate zoning map showed that the highest levels of nitrate are found in parts of the eastern, southeastern, and northern regions, which were also identified as the most vulnerable regions by vulnerability models. Also, according to the results of the regression test, for a more accurate study of the models, there is a significant linear relationship between all three models with the nitrate map. Accordingly, it was the most efficient

Table 15. Statistical results of single-parameter sensitivity analysis for composite DRASTIC index

\begin{tabular}{|c|c|c|c|c|c|c|}
\hline \multicolumn{4}{|c|}{ Effective weight (\%) } & \multirow{2}{*}{$\begin{array}{l}\text { Theoretical } \\
\text { weight (\%) }\end{array}$} & \multirow{2}{*}{$\begin{array}{c}\text { Theoretical } \\
\text { weight }\end{array}$} & \multirow{2}{*}{ Parameters } \\
\hline SD & Min. & Max. & Ave. & & & \\
\hline 4.72 & 2.90 & 23.36 & 6.44 & 17.86 & 5 & D \\
\hline 2.68 & 8.82 & 20.61 & 14.73 & 14.29 & 4 & $\mathrm{R}$ \\
\hline 4.22 & 2.80 & 16.66 & 10.74 & 10.71 & 3 & A \\
\hline 2.53 & 2.46 & 11.62 & 6.61 & 7.14 & 2 & S \\
\hline 2.60 & 5.10 & 14.28 & 8.32 & 3.57 & 1 & $\mathrm{~T}$ \\
\hline 5.86 & 7.14 & 31.05 & 18.50 & 17.86 & 5 & 1 \\
\hline 4.38 & 2.80 & 19.04 & 11.30 & 10.71 & 3 & C \\
\hline 7.50 & 14.53 & 42.85 & 23.31 & 17.86 & 5 & L \\
\hline
\end{tabular}

Table 16. Summary of the results of regression analysis

\begin{tabular}{lcc}
\hline Model & R Square & $\boldsymbol{P}$ value \\
\hline DRASTIC & 0.286 & 0.000 \\
CD & 0.350 & 0.000 \\
NV & 0.694 & 0.000 \\
\hline
\end{tabular}

Nitrate $=0.0439($ DRASTIC $)+8.9123$

Nitrate $=0.0497(C D)+6.9446$

Nitrate $=0.0677(\mathrm{NV})+9.5956$
NV model, followed by the CD and DRASTIC models, respectively. Based on the results of the two-parameter sensitivity analysis and the sinle-parameter analysis, the most influential parameter in assessing the vulnerability of the studied aquifer was the environmental media factor.

\section{Acknowledgments}

The authors of this study would like to thank the Kerman Regional Water Authority for their cooperation in data collection.

\section{Ethical issues}

The authors hereby certify that all data collected during the research are as expressed in the manuscript, and no data from the study has been or will be published elsewhere separately.

\section{Competing interests}

The authors declare that they have no conflict of interests.

\section{Au'thors contributions}

All authors contributed to data collection, analysis, and interpretation. All authors reviewed, refined, and approved the manuscript

\section{References}

1. Rahmn A. A GIS based DRASTIC model for assessing groundwater vulnerability in shallow aquifer in Aligarh, India. Applied Geography 2008; 28(1): 32-53. doi: 10. 1016/j.apgeog.2007.07.008.

2. Sinan M, Razack M. An extension to the DRASTIC model to assess groundwater vulnerability to pollution: application to the Haouz aquifer of Marrakech (Morocco). Environmental Geology 2009; 57(2): 349-63. doi: 10.1007/ s00254-008-1304-2.

3. Tilahun K, Merkel BJ. Assessment of groundwater vulnerability to pollution in Dire Dawa, Ethiopia using DRASTIC. Environmental Earth Sciences 2010; 59(7): 1485-96. doi: 10. 1007/s12665-009-0134-1.

4. Wang Y, Merkel BJ, Li Y, Ye H, Fu S, Ihm D. Vulnerability of groundwater in Quaternary aquifers to organic contaminants: a case study in Wuhan City, China. Environmental Geology 2007; 53(3): 479-84. doi: 10.1007/ s00254-007-0669-y.

5. Moratalla Á, Gómez-Alday JJ, Sanz D, Castaño S, De Las Heras J. Evaluation of a GIS-Based integrated vulnerability risk assessment for the mancha oriental system (SE Spain). Water Resour Manage 2011; 25(14):3677. doi: 10.1007/ s11269-011-9876-0.

6. Awawdeh MM, Jaradat RA. Evaluation of aquifers vulnerability to contamination in the Yarmouk River basin, Jordan, based on DRASTIC method. Arabian Journal of Geosciences 2010; 3(3): 273-82. doi: 10.1007/s12517-0090074-9.

7. Neshat A, Pradhan B. Evaluation of groundwater vulnerability to pollution using DRASTIC framework and GIS. Arabian Journal of Geosciences 2017; 10(22):501. doi: 10.1007/s12517-017-3292-6.

8. Jafari SM, Nikoo MR. Groundwater risk assessment based 
on optimization framework using DRASTIC method. Arabian Journal of Geosciences 2016; 9(20):742. doi: 10.1007/s12517-016-2756-4.

9. Sinha MK, Verma MK, Ahmad I, Baier K, Jha R, Azzam R. Assessment of groundwater vulnerability using modified DRASTIC model in Kharun Basin, Chhattisgarh, India. Arabian Journal of Geosciences 2016; 9(2): 1-22. doi: 10.1007/s12517-015-2180-1.

10. Neshat A, Pradhan B, Dadras M. Groundwater vulnerability assessment using an improved DRASTIC method in GIS. Resour Conserv Recy 2014; 86:74-86. doi: 10. 1016/j. resconrec.2014.02.008.

11. Fijani E, Nadiri AA, Asghari Moghaddam A, Tsai FT, Dixon BM. Optimization of DRASTIC method by supervised committee machine artificial intelligence for groundwater vulnerability assessment in Maragheh-Bonab plain aquifer, Iran. Journal of Hydrology 2013; 503: 89-100. doi: 10.1016/j. jhydrol.2013.08.038.

12. Mogaji K, Lim H, Abdullah K. Modeling groundwater vulnerability prediction using geographic information system (GIS)-based ordered weighted average (OWA) method and DRASTIC model theory hybrid approach. Arabian Journal of Geosciences 2014; 7(12): 5409-29. doi: 10.1007/s12517-013-1163-3.

13. Hao J, Zhang Y, Jia Y, Wang H, Niu C, Gan Y, et al. Assessing groundwater vulnerability and its inconsistency with groundwater quality, based on a modified DRASTIC model: a case study in Chaoyang District of Beijing City. Arabian Journal of Geosciences 2017; 10(6):144. doi: 10.1007/s12517-017-2885-4.

14. Huan H, Wang J, Teng Y. Assessment and validation of groundwater vulnerability to nitrate based on a modified DRASTIC model: a case study in Jilin City of northeast China. Sci Total Environ 2012; 440: 14-23. doi: 10.1016/j. scitotenv.2012.08.037.

15. Mimi ZA, Mahmoud N, Madi MA. Modified DRASTIC assessment for intrinsic vulnerability mapping of karst aquifers: a case study. Environmental Earth Sciences 2012; 66(2): 447-56. doi: 10.1007/s12665-011-1252-0.

16. Javadi S, Kavehkar N, Mousavizadeh M, Mohammadi K. Modification of DRASTIC model to map groundwater vulnerability to pollution using nitrate measurements in agricultural areas. J Agr Sci Tech 2011; 13(2): 239-49.

17. Modabberi H, Rahbar Hashemi MM, Ashournia M, Rahimipour MA. Sensitivity analysis and vulnerability mapping of the guilan aquifer using DRASTIC method. Review of Environment and Earth Sciences 2017; 4(1): 27 41. doi: 10.18488/journal.80.2017.41.27.41.

18. Souleymane K, Zhonghua T. A novel method of sensitivity analysis testing by applying the DRASTIC and fuzzy optimization methods to assess groundwater vulnerability to pollution: the case of the Senegal River basin in Mali. Nat Hazards Earth Syst Sci 2017; 17(8): 1375-92. doi: 10.5194/ nhess-17-1375-2017.

19. Pourkhosravani M. Qualitative analysis of Orzooiyeh plain groundwater resources using GIS techniques. Environ Health Eng Manag 2016; 3(4): 209-15. doi: 10.15171/ EHEM.2016.21.

20. Djémin JE, Kouamé JK, Deh KS, Abinan AT, Jourda JP. Contribution of the sensitivity analysis in groundwater vulnerability assessing using the DRASTIC method: application to groundwater in dabou region (Southern of Côte d'Ivoire). Journal of Environmental Protection 2016; 7(2): 129-43. doi: 10.4236/jep.2016.71012.

21. Choramin M, Safaei A, Khajavi S, Hamid H, Abozari S. Analyzing and studding chemical water quality parameters and its changes on the base of Schuler, Wilcox and Piper diagrams (project: Bahamanshir River). WALIA Journal 2015; 31(S4): 22-27.

22. Malakootian M, Nozari M. Contribution of the Sensitivity Analysis in Groundwater Vulnerability Assessing Using the 1 DRASTIC and Composite DRASTIC Indexes. Nat. Hazards Earth Syst Sci Discuss 2019; 1-32. doi: 10.5194/ nhess-2019-181.

23. Baghapour MA, Fadaei Nobandegani A, Talebbeydokhti $\mathrm{N}$, Bagherzadeh S, Nadiri AA, Gharekhani $\mathrm{M}$, et al. Optimization of DRASTIC method by artificial neural network, nitrate vulnerability index, and composite DRASTIC models to assess groundwater vulnerability for unconfined aquifer of Shiraz Plain, Iran. J Environ Health Sci Eng 2016; 14:13. doi: 10.1186/s40201-016-0254-y.

24. Baghapour MA, Talebbeydokhti N, Tabatabaei SH, Fadaei NA. Assessment of groundwater nitrate pollution and determination of groundwater protection zones using DRASTIC and composite DRASTIC (CD) models: the case of Shiraz unconfined aquifer. J Health Sci Surveillance Sys 2014; 2(2): 54-65.

25. Barber C, Bates L.E, Barron R, Allison H. Assessment of the relative vulnerability of groundwater to pollution: a review and background paper for the conference workshop on vulnerability assessment. AGSO J Aust Geol Geophys 1993; 14(2-3): 1147- 54.

26. Napolitano P, Fabbri A.G. Single-parameter sensitivity analysis for aquifer vulnerability assessment using DRASTIC and SINTACS. HydroGIS 96: Application of geographical information systems in hydrology and water resources management (proceedings of vienna conference. IAHS Pub 1996; 235: 559-66.

27. Manson C.F, Saboda A. Biology of Freshwater Pollution. 2nd edition, longman scien-tific and technical. John Wiley and Sons, Inc., New York; 1990, 351.

28. Colins J, Sashikkumar M.C, Anas, P. A, Kirubakaran, M. GIS-based assessment of aquifer vulnerability using DRASTIC Model: A case study on kodaganar basin. Earth Sci. Res. J 2016; 20 (1): 1-8.doi: 10.15446/esrj.v20n1.52469. 